\title{
i
}

\section{Didática da língua escrita: uma proposta metodológica e de pesquisa na área de italianística Cecilia Casini}

Resumo: A partir da reconsideraçāo dos mecanismos da oralidade e da reflexāo sobre as habilidades lingǘsticas e comunicativas que norteiam a produção textual, encontra espaço um projeto de pesquisa para a didática da língua italiana escrita. Os textos produzidos pelos estudantes vêem a ser o instrumento concreto para a elaboração de estratégias especlficas de ensino para lusófonos; a ediçāo de uma newsletter periódica em italiano, para a qual convergiria o material escrito, o momento sintetizador e produtor de consciência de todo o processo de aprendizado.

Palavras-chaves: texto; língua italiana escrita; didática; newsletter periódica.

A escrita, enquanto expressāo da vontade de comunicação, nos acompanha idealmente desde os nossos mais antigos ancestrais, ajustando-se cada vez mais conforme os diferentes códigos, formas e sistemas simbólicos de representaçāo do mundo, mantendo inalterada, no encontro com as novas tecnologias, a atenção às suas finalidades e aos seus usuários, seja por parte dos produtores, seja por parte dos receptores.

Reflexōes teóricas (e ideológicas) sobre as razōes e a prática da escrita parecem tê-la precedida ou acompanhada sempre, ao longo de sua existência. Causa certa estranheza, portanto, constatar sua relativa ausência no âmbito do ensino dos vários niveis escolares em países como o Brasil. Mas em geral na Itália também a única ocasiāo "institucionalizada" - que pode contar com uma orientaçāo por parte dos docentes - de contato com a prática da escrita antes de ingressar na faculdade, éo compito di italiano, a redação mensal sobre assuntos diferentes, em que os alunos podem expressar-se por escrito, com um texto argumentativo e não privado; e, especialmente nos liceus, as traduçōes dos outros idiomas ensinados como LE (inglês, 
francês, alemăo) e das línguas clássicas (grego e latim), essas últimas tendo como referência as regras de brevitas, inventio e dispositio da retórica clássica.

No mundo universitário italiano escreve-se pouco, mesmo em Ll; mas a recente reforma do Esame di Stato, no sentido de promover a variedade textual argumentativa (com provas que incentivam competências específicas na produção de textos diferentes, quais artigos de apreciação ou comentários, resenhas, ensaios), já começou a modificar esse quadro. Além disso, já surgiram e continuam surgindo experiências de didática da língua escrita em várias faculdades: entre elas, o pioneiro S.I.S., Servizio d'Italiano Scritto, junto à Faculdade Ca' Foscari de Veneza, voltado mais especificamente ao italiano profissional, criado em 1996 por Francesco Bruni e Tommaso Raso; a de Carmen Dell'Aversano, Alessandro Grilli e Mirko Tavoni junto à Universidade de Pisa; a de Gabriella Alfieri junto à Universidade de Catania; o projeto de Giovanni Acerboni, especificamente referente às modalidades da escrita multi-medial; acrescente-se a estes o caso da Scuola Holden de escritura criativa mantida por Alessandro Baricco em Turim.

$\mathrm{Na}$ terra do "homem cordial", no Brasil, pensar em uma didática da escrita significa fundamentalmente repensar a comunicaçāo. Pelo que diz respeito ao ensino dos idiomas estrangeiros, o que permeia todo o processo de aprendizagem é a preocupação pela interdisciplinaridade, em que se harmonizariam as competências "comunicativa", "gramatical ou lingüística", "socio-lingüística" e "discursiva e extratégica" (Célia, 1988: 333). Quanto à língua portuguesa na sala de aula, a discussão dos profissionais da área gira em torno dos Parâmetros Curriculares Nacionais (PCNs), de 1998, realizados conforme a teoria bakhtiniana sobre os gêneros do discurso enquanto esferas "de utilização da língua", que elaboram cada uma "seus tipos relativamente estáveis de enunciados" (Bakhtin, 1979: 95). Baseada nesses conceitos e nos de Lev Vygotsky, Beth Brait reflete sobre a abrangência do ensino lingüístico:

Produzir linguagem significa produzir discursos: dizer alguma coisa a alguém, de uma determinada forma, em um determinado contexto histórico e em determinadas circunstâncias de interlocuçāo. Isso significa que as escolhas feitas ao produzir um discurso nāo sāo aleatórias - ainda que possam ser inconscientes -, mas decorrentes das condiçōes em que o discurso é realizado. (...) Isso tudo 
determina as escolhas do gênero no qual o discurso se realizará, dos procedimentos de estruturação e da seleção dos recursos lingüisticos (...) O discurso quando produzido manifesta-se lingüisticamente por meio de rexros (Rojo, 2000).

Logo, parece existir, no Brasil, um ambiente propício para a transposição didática das teorias lingüísticas na realidade escolar. Interesso-me aqui mais especificamente pelo texto escrito, tendo tido ocasiāo de observar, ao longo da minha vivência como professora, que existe espaço para reforçar essa esfera particular da produção lingüística. Quer se trate de L1 ou de LE, há diferentes maneiras para aproximar-se da escritura, seja como "produtores"” seja como "usuários". Existem inúmeras modalidades de textos escritos, mas como reconhecê-los? Quais as técnicas de abordagem para cada texto? Quais as formas possíveis para sua produção? É possível apreender as estrarégias de comunicação escrita? Ao final, é possível apreender a escrever, ainda mais em LE?

A escrita tem suas características específicas, que a diferenciam de todas as outras modalidades de expressão lingüística; entre as quatro habilidades, é aquela que exige as mais altas competências, pois nela convergem, potencializam-se e sintetizam-se todas as outras habilidades da comunicação ${ }^{1}$, seja na Ll, seja na LE. A escritura constitui-se como o campo de verificação das competências dos outros aspectos da língua-estímulo, exigindo o uso e o abuso das faculdades de raciocínio. De fato, a comunicação estruturada em forma de texto escrito, enquanto máquina de produçāo de sentido "in differita" (Beltramo, 2000: 12), regenera e renegocia continuamente o valor da própria linguagem como um todo, contribuindo para organizar os "materiais" de maneira mais lúcida, para que eles sejam instrumentalmente úteis à comunidade dos "usuários"; para afinar as capacidades lógico-dedutivas e argumentativas de todos que se utilizam do sistema comunicativo; para, em última análise, desenvolver e reforçar sua identidade e seu sentido de cidadania. Isso posto, o ob-

1. Já Melchiorre Cesarotti, em começo do século XIX, tinha colocado a língua escrita em um pláno superior por ela ser "il compimento e la perfezione della lingua parlata", sendo ela capaz de superar as dificuldades locais e de se afirmar como lingua legitimamente nacional. A norma do italiano escrito deve ter, conforme ele pensa, "per base l'uso, per consigliere l'esempio, e per direttrice la ragione" (Cesarotri, 1969). 
jetivo de uma correta prática da escritura é ao mesmo tempo escolar e civil: saber escrever, isto é, pôr em prática os conhecimentos lexicais, gramaticais e sintáticos apreendidos e adequá-los às diferentes exigências culturais, sociais e profissionais, é um requisito indispensável para todo cidadāo. Saber comunicar significa obter voz, ser escutado; conseqüentemente, para ser útil, seja no nível interpessoal, seja na troca entre cidadāos e organizaçōes, escolas, instituiçōes, a língua de que nós utilizamos deve ser comunicativamente eficaz, tanto em sua vertente oral, quanto na escrita; a educação lingüística vem portanto a constituir um instrumento precioso de coligação entre a esfera pública e a esfera privada de nossas vidas.

Escrever é um ato que, partindo de um sujeito (quem escreve), prevê um outro (quem lê); é uma operação de reciprocidade discursiva, em que destinatário e finalidade da escritura são os pontos cruciais norteando toda reflexão e prática a respeito; para quem e por quê se escreve, as perguntas fundamentais. A definiçāo precisa do destinatário articula toda estratégia comunicativa, pois dela decorre o diferente gerenciamento das informaçōes, o ato de projetar e de redigir o texto escrito.

O ponto de chegada da didática da língua escrita é a argumentaçāo, ou seja, a capacidade de construir, formular, compreender, analisar e criticar argumentaçōes, segundo uma ampla variedade de estilos e de registros, referentes a uma determinada tradição cultural. O momento argumentativo é aquele em que todas as competências cognitivas e lingüísticas se manifestam ao mesmo tempo; saber argumentar significa selecionar e organizar os argumentos e as informaçōes que uma determinada situação requer, gerindo diversos registros lingüísticos, utilizando-se de uma documentação e respeitando vínculos de espaço e de tempo. Enfim, argumentar significa desenvolver um raciocínio, aplicando-o às situaçōes mais diferentes.

O sistema educativo como um todo, a escola, é o lugar privilegiado da formação argumentativa, destacando-se a importância da universidade - pelo seu papel social e cultural ao mesmo tempo, e pelo fato de estar entre as maiores produtoras de textos, tanto burocráticos, quanto acadêmicos - no processo de transmissão das competências e das habilidades da escritura. É na universidade que o estudante brasileiro pode ser atraído para o "círculo virtuoso" da didática lingüística, vindo 
a ter um papel ativo no processo educativo-formativo e de elaboraçāo de textos ${ }^{2}$, tornando-se dono de uma escrita nāo abstrata ou casual, mas motivada.

A aprendizagem da LE decorre do desenvolvimento daquelas que Vygotsky define "funçōes cognitivas superiores" (conceitualizaçăo, generalização, abstração, pensamento lógico), a que a evolução da $\mathrm{Ll}$ durante a infância está estritamente ligada. As habilidades e os conhecimentos adquiridos ao longo do processo lingüístico-cognitivo em Ll passam naturalmente para a LE, transferindo nela estruturas já "regularizadas" Cabe à escola zelar para que essa "passagem" aconteça correramente; ainda mais em se tratando da língua escrita, visto a complexidade específica da operação. Valorizar o bilingüismo e formular projetos de ensino incentivando-o junto aos alunos é uma das principais atribuiçōes do sistema educativo.

É no âmbito de uma didática voltada para uma correta comunicação escrita em língua italiana que encontra seu espaço uma proposta metodológica e de pesquisa, em que a parte teórica junta-se naturalmente com a prática na sala de aula. Constatase nos fatos a dificuldade dos discentes de italiano em lidar com a escritura enquanto veículo de comunicação, o que os leva a pedir a ajuda do professor, quando se trata, por exemplo, de redigir uma carta endereçada a uma faculdade; ou fazer um pedido no consulado; ou se informar de cursos na Itália; ou, simplesmente, escrever para seus parentes na Itália. Sem contar, caso recentíssimo, as últimas votaçōes políticas na Itália, por conta das quais muitos estudantes, que queriam exercer nos fatos sua "nova" cidadania, também foram pedir orientaçāo diretamente aos docentes, na falta de outros meios de informaçōes confiáveis (pelo menos esse foi o meu caso). Disso tudo decorre conseqüentemente, como há de se esperar, uma procura maior de cursos, estágios, bolsas, ocasiōes de encontro em geral. Especialmente nesse contexto é que o domínio do canal escrito da comunicação em italiano vai

2. Lembro-me da análise de Eco a respeito das estrucuras textuais que, conforme ele pensa, coincidem com suas potenciais estratégias interpretativas: o texto, portanto, como "macchina pigra", cujo sentido deriva do processo dialético entre as estruturas retórico-textuais determinadas pelo criador e as estratégias de interpretaçāo do leitor (Eco, 1979). 
ser imprescindivel no processo de integração entre cidadāos, daqui e de além mar, podendo ser o diferencial entre uma presença mais ou menos vivida de fato, em primeira pessoa, nas decisōes que concernem a todos nós.

A partir das características precípuas do texto escrito - a possibilidade de refletir mais em sua produção, de trabalhar com tempos mais longos, de planejar o discurso de maneira diferente com relação à fala, de cuidar mais dos aspectos lingüísticos -, a didática da escrita visa principalmente a incentivar um uso mais atento da língua ${ }^{3}$, em amplo sentido. Levando em conta, por exemplo, que hoje em dia as possibilidades de desenvolvimento do "pensamento" escrito passam necessariamente pela conexōes em rede: pensemos em quanta troca lingüística realiza-se quotidianamente via internet, em como o texto é realizado e necessariamente forçado a dialogar com os meios informáticos. As novas tecnologias eletrônicas, entre as quais o computador, parecem ser ferramentas preciosas para estimular, junto aos discentes, a recuperaçāo da LE (mas também da L1) em sua prática escrita; penso que aumente muito a motivaçāo de um estudante que consiga se comunicar, via correio eletrônico e suas aplicaçōes, com amigos internautas italianos. Incentivar a "adoçāo" à distância de correspondentes em língua italiana, amigos virtuais com quem bater papo, trocar idéias, enfim, falar de cultura ou não, seria objetivar a língua escrita em algo que pode diretamente ser experimentado, utilizado, melhorado, verificado, confrontado praticamente todo dia. A língua italiana tornar-se-ia assim um amigo italiano, com quem construir solidariedade, lingüística e pessoal.

Em um primeiro momento, o público alvo seria constituido pelos estudantes universitários de italiano. A familiarização com as convençôes da argumentação científica em âmbito humanista viria possivelmente a facilitar a execução de suas tarefas acadêmicas - como, por exemplo, redigir os trabalhos de fim de curso -, em italiano como em português (pois, em linha geral, o estudo de um idioma que não

3. "Cerco di parlare il meno possibile, e se preferisco scrivere è perché scrivendo posso correggere ogni frase tante volte quanto è necessario per arrivare (...) a eliminare le ragioni d"insoddisfazione di cui posso rendermi conto "(Calvino, 2000: 66). 
seja o próprio melhora este também, promovendo a conscientização do aluno sobre as estratégias que ele usa para aprender); ampliar-se-ia, assim, o alcance da língua italiana quanto à produção direta de material por parte dos próprios estudantes. Em um segundo momento, poder-se-ia pensar em aplicar os resultados alcançados em âmbito extra-universitário também.

Como premissa indispensável, parece-me desejável levar igualmente em consideração a escrita "funcional" (juntando as necessidades específicas de quem empreende o estudo do italiano com aquelas do mundo acadêmico: elaboração de teses, redaçōes, fichamentos, currícula, relatórios, cartas, editais, comunicados, pedidos para obter bolsas etc.) e a necessidade de preservar a especificidade da língua escrita literária; língua essa entendida não como improvisação, desprovida de qualquer disciplina e aleatoriamente dependente do talento de cada um, mas como espaço argumentativo privilegiado da criatividade e da variedade dos registros expressivos, segundo um regime de liberdade vigiada em que é prevista sua sistematização didática. Não entender essas duas modalidades em termos de antagonismo, mas sim de profícuo intercâmbio, parece ser fundamental para evitar o risco de cair em uma excessiva "tecnicização" da escrita e de seu achatamento lingüístico 4 .

A abordagem à escrita se daria pela reconsideração dos mecanismos da oralidade, de maneira a chegar a uma plena consciência lingüístico-textual das diferentes estratégias usadas nas duas modalidades expressivas. Começar-se-ia incentivando a reflexão sobre as habilidades da produção escrita, no sentido de juntar a dimensão

4. Já Leopardi, em 1820, em sua célebre distinçāo entre "termini" e "parole", falando dos efeiros que a poesia deve produzir nos leitores ("idee vaghe e indefinite e vastissime e sublimissime"), admoestava para não deixar prevalecer a aridez da linguagem "scientifica” na poericidade da língua, contanto ficasse sendo mantida sua propriedade: "Le parole (...) non presentano la sola idea dell'oggetto significato, ma quando più quando meno immmagini accessorie. Le voci scientifiche presentano la nuda e circoscritta idea di quel tale oggetto, e perciò si chiamano termini perché determinano edefiniscono la cosa da tutse le parti. Quanto più una lingua abbonda di parole, tanto più è adatta alla letteratura e alla bellezza (...) son cose ben diverse la proprietà delle parole e la nudità o secchezza, e se quella dà efficacia ed evidenza al discorso, questa non gli dà altro che aridità" (Leopardi, 1937). 
comunicativa dos textos ao aspecto lingüístico dos mesmos: primeiramente, planejar-se-ia a apresentaçăo propedêutica, dentro do programa curricular de língua italiana, de algumas disciplinas (lingüística e tipologia textual, retórica, gramática italiana avançada, semiótica, teoria da argumentaçāo, pragmática, psicologia cognitiva); em um segundo momento, a partir da análise dos tipos texruais fundamentais segundo a lingülstica (descritivo, narrativo, injuntivo, expositivo, argumentativo ${ }^{5}$ ), seriam trabalhadas as habilidades associadas a cada tipo: descrição, narraçāo, argumentação. Dessa maneira, proceder-se-ia da aquisiçāo do léxico temático (textos descritivos) à da morfologia verbal (textos narrativos), à da capacidade de compreender assuntos complexos.

A próxima etapa do processo seria passar a agir diretamente com as palavras, isto é, produzir materiais (escrever textos expositivos e argumentativos), usando registros médio-altos (isso tudo, levando em conta ser impossível esgotar a pletora dos registros lingüísticos dos vários tipos de textos e que dificilmente existe um texto que corresponda a um único tipo); nessa fase, as habilidades cognitivas comuns (descrever, narrar, pedir, expor, argumentar: de fato, uma tipologia textual de caráter interlingüístico "básico e elementar, comum a todos os idiomas"; Lavinio, 2000: $\mathrm{XXX)}$ são a base de uniformidade em que o estudante brasileiro pode enxertar as especificidades ligadas à língua e cultura italiana.

Os textos produzidos pelos estudantes, resultado dessa fase de aprendizado, seriam os instrumentos concretos de que a pesquisa se utilizaria em sua análise. $O$ estudo das características dos textos, especialmente se comparados com os produzidos anteriormente, levaria a reconhecer, entre outras coisas, os processos cognitivos ativados nessa operação pelos estudantes brasileiros e as técnicas usadas para chegar à redação textual. Isso tudo permitiria identificar as estratégias mais adequadas para o ensino do italiano escrito no Brasil, de maneira a melhorar o nível do mesmo

5. Conforme uma ordem que reflete o desenvolvimento de capacidades cognitivas tidas como universais, existentes em nível pré-lingülstico, em uma esfera em que os conteúdos sāo organizados no texto (Werlich, 1976). 
com base em uma pesquisa no campo, feita in loco. A pesquisa, portanto, apontaria para as modalidades de aprendizado da língua italiana por parte de falantes do português do Brasil, e a eventual elaboração de uma metodologia específica da didática da escrita.

Muito importante seria o momento da realização dos exercícios que, já providos de uma possível solução (chave), seriam amplamente debatidos e comentados na sala de aula sob a orientação do docente. A análise e a correção dos textos elaborados seria instrumento de uma metodologia didática baseada em critérios racionais e explícitos, nunca rígidos, atentos aos aspectos pragmáticos e gramaticais e à adequaçāo comunicativa do texto; visaria, através de precisa discussão dos defeitos do texto, ser eferivamente útil para fins didáticos e obter resultados efetivos no prosseguimento dos trabalhos. Como é impossível, evidentemente, proceder à correção de todos os textos elaborados, essa seria dividida em duas fases, complementares mas distintas entre si: uma correção analítica, que vise a avaliação, ou seja, que sinalize e discuta os defeitos, gramaticais, sintáticos e comunicativos, de cada texto, correçāo que tenha como fim especificamente a didática. A partir da seleção de poucos textos, a serem corrigidos e discutidos de maneira extremamente pontual, procurar-se-ia envolver $e$ encarregar diretamente os estudantes, estimulando a correção em duplas das provas, antes mesmo de entregá-las ao docente (que ficaria como tutor de toda a operaçāo); sob garantia de manter o anonimato do autor, entende-se que a observação de textos alheios constituiria para os estudantes um momento insubstituível para melhorar suas capacidades de avaliação e produção textual. A troca e a discussão entre os estudantes em nível de análise textual seria extremamente preciosa para que o docente possa avaliar sua capacidade objetiva de produçāo e de revisão de textos.

Seria útil valer-se, durante as aulas - que dividir-se-iam em expositivas, visando passar o conteúdo teórico e nocional; e de práticas em laboratório, oficinas mais voltadas para a exercitação e a produção direta de material escrito; mais tarde, poderia-se pensar na realização de estágios, úteis para os estudantes incrementarem suas competências na produção de textos de teor mais profissional, agindo em ambientes funcionais -, de um adequado aparato multi-medial de suporte. Momento 
importante, aliás, e sintetizador de todo o processo seria a edição de uma revista eletrônica, uma newusletter periódica, totalmente em italiano, tendo por fim divulgar assuntos de língua e cultura italiana, junto ao público brasileiro, e de língua e cultura brasileira, junto ao público italiano, para a qual convergiria o material produzido pelos estudantes. Participar das atividades de redação da revista seria importante para criar nos estudantes a necessidade de utilizar-se da escrita em língua italiana, não de maneira eventual, mas pensada e continuada no progredir dos estudos, incentivando e renovando continuamente sua motivação, até que ela seja percebida como indispensável no currículo escolar.

Hoje em dia, em um percurso formativo relativo à escrita, nāo deveria faltar atençāo à textualidade da rede: o fato de nāo existir ainda uma tradição editorial nesse âmbito, uma vez que o meio virtual é ainda algo recente, deveria ser um estímulo a ocupar tal espaço. Dizem os especialistas existir, na fase atual da história da internet, uma aproximação particularmente grande entre projetistas e programadores, entre as exigências da comunicação e os instrumentos de software que podem realizá-las; estaríamos, quanto à estrutura editorial, em um momento de particular abertura na tecnologia da web (Acerboni, 2005). Portanto, é o momento ideal para experimentaçōes e pesquisas lingüísticas, visando à criação de um padrão, alternativo àquele clássico - especialmente pelo que diz respeito à linguagem dos e-mails e dos textos mais convencionais -, em que seja possível trabalhar a interatividade no sentido de chegar a um equilibrio entre a projetação de um site institucional e a redaçāo de textos. $O$ docente e o departamento de italiano encarregar-se-iam de dirigir e supervisionar a revista, mas muito me agrada pensar nela como progressivo canal da "emancipaçáo" do estudante, pelo que diz respeito à autonomia lingüística e expressiva em língua italiana, com relação ao docente. Isto é, a escritura na rede como veículo de criação e de consciência crítico-lingüística, dentro de um processo de formação efetiva, tanto no âmbito lingüístico, como no social, que venha muito naturalmente a constituir-se como ocasião única de confronto e de crescimento para os discentes de italiano, tendo em vista seu futuro acadêmico e profissional e sua plena e consciente realização enquanto cidadãos. 
ABSTRACT: Considerati i meccanismi dell'oralità e della riflessione sulle abilità linguistiche e comunicative che dirigono la produzione testuale trova spazio um progetto di ricerca sulla didattica della lingua italiana. I testi prodotti dagli studenti vengono ad essere strumenti concreti per l'elaborazione di strategie specifiche di insegnamento a lusofoni; l'edizione di uma newsletter periodica in italiano su cui convergerebbe il materiale scritto, sarebbe il momento di sintesi produttore di coscienza di tutto il processo di apprendimento.

PAROLE CHIAVE: testo; lingua italiana scritta; didattica; newsletter periodica.

\section{Bibliografia}

AA.VV. Don Lorenzo Milani. Atti del convegno di studi (Firenze 18- 20 aprile 1980). Florença: Ufficio Cultura Comune, 1981. Norma e lingua in Italia. Alcune riflessioni fra passato e presente. Milāo: Istituto Lombardo.

Accademia di Scienze e Lettere, 1997. Quadro comune europeo di riferimento per le lingue: apprendimento insegnamento valutazione.

Florença: La Nuova Italia, 2002.

Racconti dal mondo. Roma: Editrice FILEF, 1989.

ACERBONI, G. Progettare e scrivere per Internet. Milāo: McGraw-Hill, 2005.

AGATI, A. Abilità di lettura. Turim: Paravia, 1999.

ALTIERI BIAGI, M.L. Fra lingua scientifica e lingua letteraria. Pisa: Istituti Editoriali e Poligrafici Internazionali, 1998.

AMADORI, A. Mi consenta. Metafore, messaggi, simboli. Come Silvio Berlusconi ha conquistato il consenso degli italiani. Milāo: Libri Scheiwiller, 2002.

AMITRANI, A.-DI MARZIO, R. Un computer per amico. Roma: Garamond, 1995.

AUST. D.-MC KEANE PAGLIOLICO, R. Come scrivere. Parlare, leggere, ascoltare, scrivere. Perugia: Guerra, 2001.

AUSTIN, J.L. Come fare cose con le parole. Gênova: Marietti, 1987.

BAGNO, M. Gramática da língua portuguesa: tradição gramatical, midia e exclusão social. São Paulo: Loyola, 2000.

BALBONI, P (org.). Curriculo di italiano per stranieri. Roma: Bonacci, 1995.

- Didattica dell'italiano a stranieri. Roma: Bonacci, 1994.

. Educazione bilingue. Perugia: Guerra, 1996.

Le sfide di Babele. Turim: UTET, 2000.

Tecniche didattiche e processi di apprendimento linguistico. Pádua: Liviana Editrice, 1991.

BALDELLI, I. (org.). La lingua italiana nel mondo: introduzione sulle motivazioni allo studio dell'italiano.

Roma: Istituto dell'Enciclopedia Italiana, 1987. 
BAKHTIN, M.M. A estética da criação verbal. Martins Fontes: São Paulo, 1979.

BARNI, M.-VILLARINI, A. (org.). La questione della lingua per gli immigrati stranieri: insegnare, valutare e certificare l'italiano L2. Milão: Angeli, 2001.

BEAUGRANDE, R.A.-DRESSLER, W.U. Introduzione alla linguistica testuale. Bolonha: Il Mulino, 1994.

BECCARIA, G.L. Italiano. L'antico e il nuovo, il movimento, le varietà e i problemi nellitaliano d'oggi. Milāo: Garzanti, 1988.

BELTRAMO, M. Abilità di scrittura. Turim: Paravia, 2000.

BENVENISTE, E. Problèmes de linguistique générale. Paris: Gallimard, 1971.

BEREITER, C.-SCARDAMALIA, M. Psicologia della composizione scritta. Florença: La Nuova Italia, 1995.

BERNE, E. A che gioco giochiamo. Milāo: Bompiani, 1967.

Analisi transazionale. Roma: Astrolabio-Ubaldini Editore, 1971.

BERRUTO, G. Sociolinguistica dell'italiano contemporaneo. Florença: La Nuova Italia Scientifica, 1987.

BERTINETTO, M.P. "I paradossi della nozione di testo", em GOLDIN, D. (org.), Teoria e analisi del testo. Pádua: CLEUP, 1981.

BERTINETTO, M.P.-OSSOLA, C. (org.). Insegnare stanca: esercizi e proposte per l'insegnamento dellitaliano. Bolonha: Il Mulino, 1982.

BERTUCCELLI PAPI, M. Che cos'è la pragmatica. Milão: Bompiani, 1993.

BETTINELLI. G.-FAVARO, G. Litaliano per... incontrarsi lavorare vivere. Milão: Guerini Studio, 1990.

BORTONI RICARDO, S.M. Educação em lingua materna: a sociolingüistica na sala de aula. São Paulo: Parábola Editorial, 2006.

BOSC, F.-CONOSCENTI, M.-CORDA, A.-MALANDRA. A. Il computer a lezione. Turim: Paravia, 2001.

BRAIT, B. "PCNs, gêneros e ensino de língua: faces discursivas da textualidade”, em ROJO, R. (org.), A prática de linguagem em sala de aula: praticando os PCNs. São Paulo: EDUC, 2000.

BRIGHETTI, C.-MINUZ, F. Abilitd del parlato. Turim: Paravia, 2001.

BRUNI, F-ALFIERI, G.-FORNASIERO, S.-TAMIOZZO GOLDMANN, S. Manuale di scrittura e comunicazione. Milão: Zanichelli, 1997.

BRUNI, F.-RASO, T. Manuale dell'italiano professionale. Bolonha: Zanichelli, 2002.

BUTTARONI, S. Letteratura al naturale. Autori italiani contemporanei con attività di analisi linguistica. Roma: Bonacci, 1992.

CALO, R.-FERRERI, S. Il testo fa scuola. Libri di testo, linguaggi ed educazione linguistica. Florença: La Nuova Italia, 1997. 
CALVANI, A. Iperscuola. Pádua: Franco Muzzio Editore, 1994.

CALVANI, A.-Rotta, M. Fare formazione in Internet. Manuale di didattica online. Trento: Erickson, 2002.

CALVINO, I. Lezioni americane. Sei proposte per il prossimo millennio. Milāo: Mondadori, 2002.

CANETTI, E. La lingua salvata. Milão: Adelphi, 1991.

CARLINI, F. Lo stile del Web. Parole e immagini della comunicazione di rete. Turim: Einaudi, 1999.

CARRADA, L. Scrivere per internet. Milāo: Lupetti, 2000.

CARVER, R. Il mestiere di scrivere. Esercizi, lezioni, saggi di scrittura creativa. Turim: Einaudi, 1997.

CASSESE, S. Codice di stile delle comunicazioni scritte ad uso delle pubbliche amministrazioni. Roma: Dipartimento della Funzione Pubblica, 1993.

CASTELLANI POLLIDORI, O. La lingua di plastica. Nápoles: Morano, 1995.

CATRICALÀ, M.VANNINI, E. (org.) Lector in media: la didattica dellitaliano e la comunicazione. Atti del Corso svoltosi presso l'Università per Stranieri di Siena su incarico del Ministero degli Affari Esteri e d'intesa con il Ministero della Pubblica Istruzione-Direzione generale Scambi Culturali (1317/11/2000). Florença: AIDA, 2001.

CATTANA, A.-NESCI, M.T. Analisi e correzione degli errori. Turim: Paravia, 2000.

CAVARZERE, A. Oratoria a Roma. Storia di un genere pragmatico. Roma: Carocci, 1999.

CÉLIA, M. "Objetivos dos cursos de letras para a formaçāo de professores de Línguas Estrangeiras no Brasil”, em BONH, H.-VANDRESEN, P. (org.), Tópicos de lingüistica aplicada: o ensino de linguas estrangeiras. Florianópolis: Ed. da UFSC, 1988.

CERAMI, V. Consigli a un giovane scrittore. Turim: Einaudi, 1996.

CESAROTTI, M. Saggio sulla filosofia delle lingue. Milăo: Marzorati, 1969.

CHOMSKY, N. Conoscenza e libertà. Interpretare e cambiare il mondo. Roma: Net, 2004.

Problemi di teoria linguistica. Turim: Boringhieri, 1975.

Riflessioni sul linguaggio. Turim: Einaudi,1981.

CILIBERTI, A. Manuale di glottodidattica. Florença: La Nuova Italia, 1994.

. (org.). Linsegnamento linguistico per scopi speciali. Bolonha: Zanichelli, 1981.

COMRIE, B. Universali del linguaggio e tipologia linguistica. Bolonha: Il Mulino, 1983.

COMUNITA DI S. EGIDIO. Litaliano per amico. Brescia: La Scuola, 1992.

CONTE, M.E. Condizioni di coerenza. Ricerche di linguistica testuale. Alessandria: Edizioni dell'Orso, 1999.

La linguistica testuale. Milāo: Feltrinelli, 1977.

CORDER, S.P. "La lingua dell'apprendente", em ARCAINI, E.-PY, B. (org.), Interlingua. Aspetti teorici e implicazioni didattiche. Roma: Istituto dell'Enciclopedia Italiana, 1984.

. "The Significance of Learners Errors", em RICHARDS, J.C., Error Analysis. Perspectives on Second Language Acquisition. Londres: Longman, 1974. 
COSERIU, E. Linguistica del testo. Roma: La Nuova Italia Scientifica, 1997.

COVERI, L.-BENUCCI, A-DIADORI, P. Le varietà dell'italiano. Manuale di sociolinguistica italiana. Con documenti e verifiche. Siena-Roma: Bonacci, 1998.

CUNHA VICTÓRIO DE OLIVEIRA ANDRADE, M.L. "Textos construídos na internet: oralidade ou escrita?", em DA SILVA, L. A. (org.), A lingua que falamos. Português: história, variação e discurso. Rio de Janeiro: Ed. Globo, 2000.

D'ACHILLE, P. Sintassi del parlato e tradizione scritta della lingua italiana. Roma: Bonacci, 1990.

DANESI, M. Il cervello in aula: neurolinguistica e didattica delle lingue. Perugia: Guerra, 1998.

DARDANO, M. Manualetto di linguistica italiana. Bolonha: Zanichelli, 1995.

DARDANO, M.-TRIFONE, P. Grammatica italiana con nozioni di linguistica. Bolonha: Zanichelli, 2002.

DEGLINNOCENTI, R.-FERRARIS, M. Il computer nell'ora di italiano. Nuovi linguaggi e nuovi strumenti per l'educazione linguistica. Bolonha: Zanichelli, 1988.

DELLA CASA, M. Scrivere testi. Il processo, i problemi educativi, le tecniche. Florença: La Nuova Italia, 1994.

DE MAURO, T.-MANCINI, F.-VEDOVELLI, M. Lessico di frequenza dell"italiano parlato. Milāo: ETAS, 1993.

DE RIENZO, G. Guida alla scrittura. Milāo: Bompiani, 2001.

DE SAUSSURE, F. Corso di linguistica generale. Bari: Laterza, 1993.

DESIDERI, P. (org.). Multimedialità e didattica delle lingue. Perugia: Mediateca, 1999.

DIADORI, P. (org.). Insegnare italiano a stranieri. Florença: Le Monnier, 2001.

DOLCI, R.-CELENTIN, P. (org.). La formazione di base del docente di italiano per stranieri. Roma: Bonacci, 2000.

DOMINICI, G. Gli strumenti della valutazione. Nápoles: Tecnodid, 1996.

D'ORTA, M. Jo speriamo che me la cavo. Milāo: Mondadori 1990.

DRESSLER, W.U. Introduzione alla linguistica del testo. Roma: Officina, 1974.

ECO, U. Lector in fabula. Milāo: Bompiani, 1979.

FERREIRO, E.-PONTECORVO, C.-MOREIRA, N.-GARCIA HIDALGO, 1. Cappuccetto Rosso impara a scrivere. Florença: La Nuova Italia Scientifica, 1996.

FERREIRO, E.-TEBEROSKY, A. La costruzione della lingua scritta nel bambino. Florença: GiuntiBarbera, 1985.

FIORITTO, A. (org.). Manuale di stile. Strumenti per semplificare il linguaggio delle amministrazioni pubbliche. Bolonha: Il Mulino, 1997.

FIORMONTE, D.-CREMASCOLI, F. Manuale di scrittura. Turim: Bollati Boringhieri, 1998. FREIRE, P. L'educazione come pratica della libertà. Milāo: Mondadori, 1977. 
FRANCESCONI, R. L'esperienza didattica e socioculturale di don Lorenzo Milani. Modena: Centro Programmazione Editoriale, 1976.

FREDDI, G. Principi di glottodidattica. Turim: UTET, 1994.

GALLO, S. L. "O ensino da lingua 'materna’ no Brasil do século XIX: a mãe outra”, em ORLANDI, E.P. (org.), Lingua e cidadania: o português no Brasil. Campinas: Pontes, 1996.

GLACALONE RAMAT, A.-VEDOVELLI, M. (org.). Italiano lingua secondallingua straniera. Atti del XXVI Congresso della Società di Linguistica Italiana. Roma: Bulzoni, 1992.

GIDE, A. I consigli a un giovane scrittore. Milão: Archinto, 1993.

GINEPRINI, M.-RONCALLO, A. La scrittura emergente. Soveria Mannelli: Rubbertino, 2002.

GREENBERG, J. "Alcuni universali della grammatica con parricolare riferimento all'ordine degli elementi significativi”, em P. RAMAT (org.), La tipologia linguistica, Bolonha: Il Mulino, 1976. GREENFIELD, P.M. Mente e media. Roma: Armando Editore, 1985.

GRUNDY, P. Doing Pragmatics. Londres: Arnold, 2000.

HALLIDAY, M.A.K. Lingua parlata e lingua scritta. Florença: La Nuova Italia, 1992.

JAFRANCESCO, E. Parla e scrivi. Florença: Lauree \& Cendali, 1993.

LACERDA ARAÚJO, I, Do signo ao discurso: introdụ̧āo à filosofia da linguagem. São Paulo: Parábola Editorial, 2005.

LAING, R. L'Jo e gli altri. Florença: Sansoni, 1969.

LANDOW, G. Ipertesti: la convergenza della tecnologia e della critica letteraria. Bolonha: Baskerville, 1993.

LAVINIO, C. Le abilità di scrittura. IRRSAE Liguria: 1994.

"Tipi testuali e processi cognitivi", em CAMPONOVO, F-MORETTI, A. (org.), Didattica ed educazione linguistica. Florença: La Nuova Italia, 2000.

LEFFA, V.-PAIVA, M. de G. O processo de aprendizagem de uma lingua estrangeira. Porto Alegre: Editora da UFRGS, 1993.

LEOPARDI, G. Zibaldone di pensieri. Milão: Mondadori, 1937.

LEPSCHKY, G. C. La linguistica del Novecento. Bolonha: Il Mulino, 1992.

LEPSCHY, G.C.-LEPSCHY, A. L. La lingua italiana: storia, varietà dell'uso, grammatica. Milāo: Bompiani, 1986.

LEPSCHKY, G.C.-RAPONI, L. Nuovi saggi di linguistica italiana. Bolonha: Il Mulino, 1989.

LEVINSON, S.C. La pragmatica. Bolonha: Il Mulino, 1993.

LO CASCIO, V. Grammatica dell'argomentare: strutture e strategie. Florença: La Nuova Italia, 1991. LODGE, D. (org.) Il mestiere di scrivere. Roma: Fazi Editore, 1998.

LORENZETTI, R. Compagni di viaggio. Bolonha: CLUEB, 1999.

LUCCHINI, A. Scrivere, una fatica nera. Miläo: Comunico, 1997. 
MACHADO, A.R.-LOUSADA, E.- SANTOS ABREU TARDELLI, L. Planejar gêneros acadêmicos.

Sāo Paulo: Parábola Editorial, 2005.

Resenha. São Paulo: Parábola Editorial, 2004.

MAGGINI, M. "Apprendimento linguistico e ruolo delle glottotecnologie", em VANNINI, E. (org.), Atti del corso di formazione iniziale per il personale della Scuola Secondaria da destinare all'estero (30/09-30/10-1996). Siena: Ministero degli Affari Esteri-Università per Stranieri di Siena, 1998.

"Multimedialità e didattica", em MICHELI, P. (org.), Audiovisivi e didattica dell'italiano L2. Bibliografia ragionata. Florença: Edizioni Aida, 1999.

MANSFIELD, K. La passione della scrittura. Milão: La Tartaruga, 1995.

MARAGLIANO, R. Nuovo manuale di didattica multimediale. Bari, Laterza, 1998.

MARAGLIANO, R.-VITALI, L. Videoscrivere in classe. Roma: Editori Riuniti, 1990.

MARAINI, D. Amata scrittura. Laboratorio di analisi letture proposte conversazioni. Milão: BUR La Scala, 2002.

MARGIOTTA, U. Pensare in rete. Bolohna: CLUEB, 1997. (org.). Linsegnante di qualità. Roma: Armando Editore (CEDE), 1999.

MARTINS, E. Com todas as Letras. O português simplificado. São Paulo: Moderna, 1999. MASTURZO, M.L.-MELI, L. A righe scoperte - Itinerari di scrittura. Turim: Eurelle, 1993. MEZZADRI, M. Internet nella didattica dell'italiano. La frontiera presente. Perugia: Guerra, 2001. MILANI, don L. Lobbedienza non è più una virtù. Florença: LEF, 1965.

MONI, A. Scriviamo! Attività per lo sviluppo dell'abilità di scrittura. Atenas: Edilingua, 2000.

MOLLICA, A. Parole crociate per principianti. Welland: Soleil, 1991.

MORETTI, G.B. Litaliano come prima o seconda lingua nelle sue varietà scritte e parlate. Perugia: Guerra, 2005.

MORTARA GARAVELLI, B. Il filo del discorso. Turim: Giappichelli, 1979.

"Italienisch: Textsorten/Tipologia dei testi", em G.HOLTUS-M.METZELTIN-C.SCHMITT

(org.) Lexicon der Romanistischen Linguistik (vol.IV). Tübingen: Niemeyer, 1988.

NEVES, M.H. de Moura. Gramática de usos do português. São Paulo: Editora UNESP, 2000.

NADOLSKIS, H. Comunicagãao redacional atualizada. São Paulo: USP, 1999.

NIELSEN, J. Designing Web Usability. Los Angeles: New Riders, 2000.

ONG, W. Oralità e scrittura. Turim: Il Mulino, 1984.

OTT, M.-RATTI, D.-TAVELLA, M. Italiano col computer. Bolonha: Zanichelli, 1988.

OTTONI, P. Visão performática da linguagem. Campinas: Editora da UNICAMP, 1998.

PAGANINI, G. Issimo. Quaderno di scrittura, Livello avanzato. Roma: Bonacci, 1994.

PALLOTTI, G. La seconda lingua. Milāo: Bompiani, 1998.

PECHEUX, M. O discurso: estrutura ou acontecimento. Campinas: Pontes, 1990. 
PÉCHEUX, M. Semantica e discurso: uma critica à ajirmaşāo do óbvio. Campinas: Editora da UNICAMP, 1998.

PENGE, S. Storia di un ipertesto. Leggere, scrivere e pensare in forma di rete, con il software. Florença: Il campo dei miracoli, 1996.

PERELMAN, C.-OLBRECTS TYECA, L. Trattato dell'argomentazione. Turim: Einaudi, 2005.

PLANTIN, C. L'argumentation. Paris: Le Seuil, 1996.

PONTECORVO, C. “La mente argomentativa”, em Rassegna di Psicologia, n. 1, 1997. Roma: Dipartimento di Psicologia e di Psicologia dei Processi di sviluppo e Socializzazione-La Sapienza.

Manuale di psicologia dell'educazione. Bolonha: Il Mulino, 1999.

PORCELLI, G. Educazione linguistica e valutazione. Turim: UTET, 1998.

Computer e glottodidattica. Pádua: Liviana Editrice, 1988.

PROVENZANO, C. Pretesti per leggere e scrivere. Bolzano: Praxis, 1991.

QUINE, W. VAN ORMAN. Manuale di logica. Milāo: Feltrinelli, 1960.

RASO, T. "Origine e strategia dell'informazione in alcune testualità burocratiche", em Stzudi linguistici italiani, n.25 e 26, 1999 e 2000.

RUGARLI, G. Manuale del romanziere. Veneza: Marsílio, 1998.

RUSSEL, B. Introduzione al Tractatus Logico-Philosophicus di L. Wittgenstein. Milāo-Roma: Fratelli Bocca Editori, 1954.

SABATINI, F. La comunicazione e gli usi della lingua. Pratica, analisi e storia della lingua italiana. Turim: Loescher, 1984.

- Linguistica testuale comparativa. Copenhagen: Museum Tusculanum Press, 1999.

. "L'italiano dell'uso medio: una realtà tra le varietà linguistiche italiane", em HOLTUS, G.RADTKE, E. (org.), Gesprochenes Italienisch in Geschichte und Gegenwart. Tübingen: Nar, 1985.

"Rigidità-esplicitezza vs elasticità-implicitezza: possibili parametri massimi per una tipologia dei testi”, em Linguistica testuale comparativa. Copenhagen: Museum Tusculanum Press, 1999.

SABATO, E. El escritor y sus fantasmas. Buenos Aires: Emecé Editores, 1976.

SBISA, M. Gli atti linguistici. Milão: Feltrinelli, 1978.

SCAVETTA, D. Le metamorfosi della scrittura. Florença: La Nuova Italia, 1992.

SCHOPENAUER, A. L'arte di ottenere ragione. Milāo: Adelphi, 1991.

SELINKER, L. "Interlingua", em ARCAINI, E.-PY, B. (org.), Interlingua. Aspetti teorici e implicazioni didattiche. Roma: Istituto dell'Enciclopedia Italiana, 1984.

SEMPLICI, S. (org.) Verifica, valutazione e certificazione delle competenze. Siena: Università per Stranieri, 1997.

SERAFINI, M.T. Come si scrive. Miläo: Bompiani, 1992.

SERIANNI, L. "Il problema della norma linguistica nell'italiano" em Annali dell'Università per Stranieri di Perugia, n.7, 1986. 
SERIANNI, L.-DELLA VALLE, V.-PATOTA, G. Litaliano - La norma e l'uso della lingua - Analisi e produzione del testo. Milāo: Archimede, 1993.

SERIANNI, L.-TRIFONE, P. Scritto e parlato. Turim: Einaudi, 1994. (org.). Storia della lingua italiana. II. Scritto e parlato. Turim: Einaudi, 1994.

SERRA BORNETO, C. Testi e macchine. Una ricerca sui manuali di istruzioni per l'uso. Milão: Franco Angeli, 1992.

SIMONE, R. La terza fase. Roma-Bari: Laterza, 2000.

SKINNER, B.F. Verbal Behaviour. Nova Yorque: Appleton, 1957.

SOBRERO, A. Bricolingua italiana ... e dintorni. Il libro delle abilità. Bari: Laterza, 1999.

(org.). Introduzione all'italiano contemporaneo. Le strutture. La variazione e gli usi. Roma-Bari: Laterza, 1993.

SPINA, S. Parole in rete. Florença: La Nuova Italia, 1992.

STELLA, G.-STRADI, C. Il gioco di leggere e scrivere: $i$ processi di alfabetizzazione spontanea nella scuola dell'infanzia. Bergamo: Iuvenilia, 1991.

STELLA, G.-NARDOCCI, F. (org.). Il bambino inventa la scrittura. Roma: Franco Angeli, 1992.

TESTA, A. Farsi capire. Milāo: Rizzoli, 2000.

TITONE, R. Problemi di psicopedagogia del linguaggio: dalla psicolinguistica alla glottodidattica. Perugia: Guerra, 1998.

TOULMIN, S. Gli usi dell'argomentazione. Turim: Rosemberg \& Sellier, 1975.

TRENTIN, G. (org.) Telematica e didattica. Ortona: Menabò, 1992.

TRONCARELLI, D.-VANNINI, E. L'arte del costruire. Roma: Bonacci, 1994.

TURCHETTA, B. Il mondo in italiano. Varietà e usi internazionali della lingua. Bari: Laterza, 2005.

VAN DIJK, T.A. Testo e contesto. Studi di semantica e pragmatica del discorso. Bolonha: Il Mulino, 1980.

VEDOVELLI, M. "La lingua italiana d'uso: morfosintassi del parlato e dello scritto", em PROGETTO MILIA, Materiali per gli insegnanti di Lingua Italiana - Aggiomamento. Liguria: IRRSAE, 1995.

VENTURELLI, A. Dal gesto alla scrittura. Milăo: Mursia, 2004.

VERGARO, G. "Nuove tecnologie e didattica delle lingue", em SERRA BORNETO, C., C'era una volta il metodo. Roma: Carocci, 1998.

VERRI MENZEL, R. La bottega dell'italiano. Antologia di scrittori italiani del Novecento. Roma: Bonacci, 1992.

VIANA, A.C. (org.) Roteiro de redação. Lendo e argumentando. Sāo Paulo: Scipione, 1998.

VITALI, L. Il videogioco della scrittura. Roma: Anicia, 1993.

VYGOTSKIJ, L. S. Pensamento e Linguagem. Martins Fontes: São Paulo, 1998. 
WATZLAWICK, P.-HELMICK BEAVIN, J-JACKSON, D. Pragmatica della comunicazione umana.

Roma: Astrolabio, 1971.

WEINRICH, H. Lingua e linguaggio nei testi. Milāo: Feltrinelli, 1988.

WERLICH, E. A text grammar of English. Heidelberg: Quelle und Meyer, 1976.

WHORF, B. LEE. Linguaggio pensiero e realtà. Turim: Boringhieri, 1970.

WOOLF, V. Il lettore comune. Sul dorso di unidea. Gênova: Il Melangolo, 1995.

ZARATE, G. Enseigner une culture étrangère. Paris: Hachette, 1986.

ZUCCHERMAGLIO, C. Gli apprendisti della lingua scritta. Bolonha: Il Mulino, 1998.

Textos encontrados na internet (autores: Ugo Cardinale, Carmen Dell'Aversano, Maria Zaleska,

Tommaso Raso, Giovanni Acerboni, Sara D'Ascenzo, Simona Beccone, Gabriella Alfieri, Mirko

Tavoni, Paolo Balboni)

Alguns dos principais siles sobre língua italiana pesquisados:

www.italianoscritto.com

www.jtalicon.it

wwww.italica.rai.it

www.linguanet.it

www.linguanet-europa.org

www.piazzadante. it 